\title{
Independent or Dependent? European Labour Statistics and Their (In)ability to Identify Forms of Dependency in Self-employment
}

\author{
Rossella Bozzon $^{1}$ (D) Annalisa Murgia ${ }^{1}$ (D)
}

Accepted: 8 September 2021 / Published online: 25 September 2021

(c) The Author(s) 2021

\begin{abstract}
In the studies on labour market change and transformation of employment relations, the growth of new forms of self-employment, including platform work, has raised a broad debate about how to define, classify, and analyse the wide range of positions within the heterogeneous category of self-employed workers. This article analyses the emergent methodologies used in European comparative labour statistics to identify forms of dependency in self-employment. Using the 6th wave of the 2015 European Working Condition Survey and the 2017 ad hoc module on self-employment from the European Labour Force Survey, this article discusses how the representation of dependent self-employment changes by adopting a different operationalization of economic and operational dependency. Findings show how different indicators of dependency change the representation of self-employment in different economic sectors, affecting our understanding of the transformation of working arrangements within self-employment and the boundaries between employment and self-employment.
\end{abstract}

Keywords Self-employment · Dependent self-employment · Dependent contractors · Economic dependency $\cdot$ Operational dependency

\section{Introduction}

In the European political and public debates on the transformation of employment relations, the recent revival of self-employment has raised broad discussions about how to measure, classify and represent the wide variety of working conditions within this working status. Self-employment, indeed, includes heterogeneous positions, both online and offline, which range from 'pure' entrepreneurs, 'traditional' own account workers,

Rossella Bozzon

rossella.bozzon@unimi.it

https://www.unimi.it/it/ugov/person/rossella-bozzon

Annalisa Murgia

annalisa.murgia@unimi.it

https://www.unimi.it/en/ugov/person/annalisa-murgia

1 Department of Social and Political Sciences, University of Milan, Milan, Italy 
and independent professionals, to work arrangements that are formally self-employed, but hide dependent working conditions or combine self-employment with dependent employment (Burke, 2015; Cieślik \& Dvoulety, 2019; Conen \& Schippers, 2019; Semenza \& Pichault, 2019; Tremblay, 2008). These emerging forms of self-employment are a consequence of rationalization and marginalization processes which lead to the development of weak job positions, with low levels of protection and employment rights fostering the diversification of work arrangements as well as labour market dualization between insiders and outsiders (Lindbeck \& Snower, 2001; Rueda, 2014; Smeaton, 2003).

While the debates on labour market changes due to processes of flexibilization and technological changes are rather well established in economic, political, and social fields (Emmenegger et al., 2012; Goos et al., 2014), the recent changes in work arrangements, accompanied by the progressive spread of digital labour platforms, are posing new challenges to the analysis of contemporary work, economies, and societies (Behrendt et al., 2019; Kurer \& Palier, 2019; Meyer, 2019). In this context, public statistics are also struggling to represent and monitor these changes. Consolidated definitions and measures employed by labour force surveys have been challenged by the erosion of the traditional classification of work arrangements rooted in the employment versus self-employment dichotomy, on which not only labour statistics, but also legal definitions and welfare regimes have hitherto relied (Murgia et al., 2020). To describe these changes and the blurred boundaries between employment and self-employment, categories like 'dependent' self-employed (Eurofound, 2017; Eurostat, 2018; Williams $\&$ Horodnic, 2018, 2019), 'quasi' (Kautonen \& Kibler, 2016) or 'false' and 'bogus' selfemployed (Thörnquist, 2015), as well as 'dependent contractors' (ILO, 2018a, 2018b, 2018c), have received growing attention in national and European official statistics. However, there is a lack of agreement on how to measure these emergent work arrangements, especially within the macro category of self-employment.

This article aims to contribute to the debate on the measurement of non-standard job positions, including platform work. More specifically, it analyses the presence of forms of dependency within self-employment and the emergent methodologies to detect 'dependent self-employment', that is to say independent positions characterised by forms of dependency traditionally regarded as the cornerstones of dependent employment (Supiot, 1999). The debate on dependent self-employed workers is therefore assessed, focusing on how the development of this category of workers intersects with the methodologies of measurement and classification of self-employment adopted by the main labour force surveys in Europe (and fixed by ILO, 1993, 2018a, 2018b, 2018c). First, we discuss the development of dependent self-employment and the definitions of economic and operational dependency to trace the border between genuine and dependent self-employed positions. Second, we analyse the methodologies developed in labour force surveys to identify dependent self-employment beyond national labour market specificities. Then, we test different methodologies of operationalization of economic and operational dependency using two comparative databases that enclose in-depth information on self-employment positions: the 2017 ad hoc module on Self-employment of the European Labour Force Survey; and the 6th wave of the 2015 European Working Condition Survey. Our findings show how differences in the operationalization of the forms of dependency change the representation of the emerging grey areas of work within selfemployment. Finally, we discuss the main implications for different economic activities, and the potential and limits of adopting different measurements. 


\section{Self-employment and Forms of Dependency}

The debate on the grey zones of work and employment focuses on 'hidden' forms of work, which lie in an undefined area between employment and self-employment (Azaiis et al., 2017; Bisom-Rapp \& Coiquaud, 2017). In the European political and public debate, the grey areas of work became a central issue with the Supiot report for the European Commission (Supiot, 2001), which examined how changes in economic and labour relations challenged labour and social security laws in Europe. The report discussed the emergence of the so-called 'economically dependent self-employed', a category of workers who are legally independent (i.e. self-employed) but economically dependent, and positioned in the space between genuinely subordinated workers and genuinely independent entrepreneurs (Supiot, 1999). According to Supiot (1999, p. 34), economic dependency is defined by working "upon a single client or prime contractor or on a very small number of clients", thus the resultant income (or a large part of it) depends on a single employer. Therefore, economic dependency is mainly considered as the exclusiveness of the work relationship and financial support measures that tie the worker closely to the outsourcing firm by increasing the costs of outsider options (Muehlberger, 2007).

In subsequent works, scholars further refined the definitions of the self-employed status that can be traced in the grey zones between employment and self-employment. More specifically, the 'dependent self-employed' have been conceptualised as self-employed workers, who in principle should work and organise their work autonomously, but - in practice - depend only on one client or a specific firm (employer) and/or work under similar conditions as employees (Kautonen \& Kibler, 2016; Kautonen et al., 2010; Thörnquist, 2015; Williams \& Horodnic, 2018, 2019). Following this broader definition, dependent self-employed are then characterised not only by economic dependency, but also by other forms of dependency that make self-employment job conditions close to those of dependent jobs. These other forms of dependency are labelled in different ways in the literature. Early works on this topic define them as 'personal dependency' (or 'subordination') on time, place, and contents of work (Muehlberger, 2007; Muehlberger \& Pasqua, 2009). These forms of dependency make the self-employed neither clearly separated nor integrated with the firm they contract with (Eichhorst et al., 2013). Personal dependency can then be defined as the "the managerial control function of the principal" (Eichhorst et al., 2013, p. 25), and therefore indicates elements of hierarchical control in the work relationship (Eichhorst et al., 2013; Muehlberger, 2007), such as the lack of a clear organisational separation in terms of employment premises or equipment, no clear distinction of tasks that are usually performed by employees, or job 'services' that fall outside the traditional scope of 'professional services' (Pedersini, 2002). Most recent works define these forms of dependency instead as 'operational', mainly indicating the lack of autonomy in deciding the work organisation or how to run the business (ILO, 2018a, 2018b, 2018c).

The development of dependent self-employment is largely the outcome of different processes that encourage companies to use job flexibility while simultaneously shifting risk to the worker (Böheim \& Mühlberger, 2009) through hierarchical forms of outsourcing (Muehlberger, 2007) and subcontracting practices that favour a labour recommodification process (Arruñada et al., 2004; Frade \& Darmon, 2005). As stressed by Böheim and Mühlberger (2009), the organisational rationale behind these practices of externalisation is at least threefold: obtaining financial flexibility on labour costs; eluding or circumventing labour and social security laws, since self-employment relations are often excluded by employment protection; and extending the control function 
of management across organisational boundaries (Frade \& Darmon, 2005; Williams $\&$ Horodnic, 2019). These phenomena have been further exacerbated by the advent of digital labour platforms, which made the experience of labour even more fragmented and embedded in global competition (Howcroft \& Bergvall-Kåreborn, 2019; Kaine \& Josserand, 2019). From a legal perspective, the development of these forms of employment relations implies shifting the regulation of employment relations from labour regulation to issues related to trade relations and commercial law (Countouris \& De Stefano, 2019), redrawing - or in many cases excluding - access to labour and social protection regulations (Murgia et al., 2020; Digennaro, 2020). Moreover, outsourcing and subcontracting practices have shaped the forms of both economic and operational dependency that define the emerging work arrangements.

As an example, Muehlberger (2007) showed how - in the case of self-employed insurance agents who worked for an outsourcing firm - dependent employment is generated by hierarchical outsourcing practices. On the legal side, agents usually work for an outsourcing firm on the basis of a commercial contract, which transfers to the agent the entrepreneurial risk and the responsibility for their economic and social security. In this way, the outsourcing firm gains financial and organisational flexibility over labour costs, but the self-employed insurance agents are economically dependent on the relationship with the firm. Moreover, in the organisation of work, the outsourcing firm uses managerial control over the independent contractors, fixing the goals of the worker's performance and prices for performance-related payment. Thus, the outsourcing firm decides how the work must be performed, as they do in an employment relationship (operational dependency).

In the transportation and storage sector, instead - as effectively shown in Ken Loach's movie Sorry We Missed You (2019) - the development of dependent self-employment concerns truck drivers who own their truck and run a trucking company but work only for one forwarding company (economic dependency), which determines the work schedule and the brand and visual identity of the trucks (operational dependency). Thus, the trucking company decides when and how the self-employed must work. The self-employed truck drivers bear the economic risk because they support the costs and risks of the functioning of the truck, they earn when they work, and they are responsible for social insurance contributions (Arruñada et al., 2004; Eichhorst et al., 2013). A further example of dependent selfemployment in the transportation sector is taxi drivers, especially in the platform economy, who own or lease their vehicle but who depend on 'access' to their clients from a taxi dispatching service, which fixes the cost of the service (economic dependency) and the organisation of the work (operational dependency) while the drivers remain directly responsible for taxation and social security contributions (ILO, 2018a, 2018b, 2018c). Similar situations apply in general to jobs provided by digital labour platforms, such as delivery services (e.g. Glovo, Just Eat or Deliveroo) and crowd-work (e.g. Amazon Mechanical Turk), where economic costs, working times and tasks are set by digital labour platforms, which, however, employ workers mainly as self-employed (Borghi et al., 2021; Howcroft \& Bergvall-Kåreborn, 2019; Kaine \& Josserand, 2019).

The conditions for the development of dependent self-employment can also be frequently found across Europe in the cultural and care sectors, mainly due to the increase of externalization and subcontracting practices in these sectors (Frade \& Darmon, 2005). Specific conditions have occurred under which standard employees have been disguised as self-employed or autonomous subcontractors, basically to avoid constraints and obligations imposed by social protection and labour laws (Schmidt and Schwerdtner 1999; Thörnquist, 2015). These job relations are usually labelled in the debate as 'false' or 'bogus' selfemployment (Kautonen et al., 2010). 
In the attempt to identify blurred employment relations, and more specifically job relations within self-employment characterised by different forms of dependency, labour statistics have developed different methodological instruments, which result in different ways of measuring and representing dependent self-employment.

\section{Dependent Self-employment and Labour Force Surveys}

The significant changes faced by European labour legislation over the last 30 years have questioned the criteria according to which different job groups are defined in different countries and have raised the necessity for labour comparative statistics to implement new classifications for working statuses, especially regarding new forms of self-employment.

The official labour force surveys at national and European levels identify and classify employment statuses relying on the ILO Classification of Status in Employment, adopted in 1993 (ICSE-93), which split jobs into two main types: paid employment jobs (employees); and self-employment jobs (employers, own-account workers, contributing family workers and members of producers' cooperatives).

Self-employment jobs are those jobs where the remuneration is directly dependent upon the profits (or the potential for profits) derived from the goods or services produced. The incumbents make the operational decisions affecting the enterprise, or delegate such decisions while retaining responsibility for the welfare of the enterprise (ILO, 1993, p. 2)

Thus, according to ICSE-93, a self-employment position is characterised by specific powers, such as autonomy of decision-making in organising work and hiring people, financial independence and related responsibility and constraints (Eurofound, 2012; Muehlberger, 2007). Therefore, within the frame of the ICSE-93 criteria, the self-employed who do not match this description cannot be identified. This means that ICSE-93 does not allow for the classification of job situations where workers are:

(i) in a situation similar to "paid employment", but which is disguised as a selfemployment situation; or (ii) in an ambiguous situation with characteristics of both "paid employment" and "self-employment"; or (iii) working under a triangular employment relationship in which it is not clear who the real employer is, what the workers' rights are and who is responsible for them (ILO, 2003, p. 67).

In 2018, to officially address these misclassification problems, ILO adopted a resolution that overcame the ICSE-93 and established new standards to identify and classify ambiguous working statuses in the new ICSE-18 classification, shifting attention from the identification of genuine self-employment to the different forms of dependencies within selfemployment. According to the ILO Resolution document:

Dependent contractors are workers who have contractual arrangements of a commercial nature (but not a contract of employment) to provide goods or services for or through another economic unit. They are not employees of that economic unit, but are dependent on that unit for organization and execution of the work, income, or for access to the market. They are workers employed for profit, who are dependent on another entity that exercises control over their productive activities and directly benefits from the work performed by them (ILO, 2018a, p. 8). 
The new category of dependent contractors is thus very close to that of dependent selfemployed discussed in the academic debate on grey zones of work and employment illustrated in the previous section. In particular, the ILO resolution framed the dependency that characterises dependent contractors in two ways:

of an economic nature, such as be dependent on a single or other economic unit or person for access to the market, fix the price for the goods produced or services provided, or access to raw materials or capital items and/or of operational nature, through organization of the work (ILO, 2018a, p. 8).

The operational dependency denotes the lack of autonomy in taking strategic and operational decisions, or in taking decisions about when, where, and how to work. Thus, in its definition, ILO acknowledged both the economic and the operational dependencies, but the methodology to identify this employment status is still under discussion (ILO, 2018a, $2018 \mathrm{~b}, 2018 \mathrm{c})$. Indeed, there is no agreement on how to identify economic dependency and other forms of dependency embedded within the concept of operational dependency. And there is even less agreement on how to combine economic and operational dependencies to identify dependent self-employed workers or, with the ILO-proposed label, dependent contractors.

At the national level, several attempts have been made over time to quantify dependent self-employment. Böheim and Mühlberger (2009) identified (economically) dependent self-employed workers using the indicator to work for only one customer/client - available in the British Labour Force Survey - as a proxy of economic dependency. In this case, the dependent self-employed are identified only because of their economic dependency. Other estimations exploited instead the specificities of national labour laws, such as those of Spain or Italy, which comprise the presence of "an intermediate category situated between the categories of employee and independent contractor" (Cherry \& Aloisi, 2016, p. 2). Using the Italian Labour Force Survey, Muehlberger and Pasqua (2009) identified dependent self-employed workers as those individuals who are employed with 'continuous and coordinated collaborations' (collaborazioni coordinate e continuative, CO.CO.CO.), whose job conditions are close to that of dependent workers. In Spain, the labour force survey includes criteria to identify the status of economically dependent self-employed workers (trabajador autonomo economicamente dependiente, TRADE), whose income derives at least $75 \%$ from a single principal (Cherry \& Aloisi, 2016; European Commission 2018; Williams \& Horodnic, 2018). Both CO.CO.CO. and TRADE fall within the definition of dependent self-employment, but do not exhaust all possible cases of dependent selfemployment that may be found in the Italian and Spanish labour markets. The criteria fixed by national legislation and labour force surveys have nevertheless guided the development of statistical indicators of economic dependency implemented in comparative surveys.

At the comparative European level, key attempts to identify dependent self-employment have been performed more recently, in particular by Eurofound in the European Working Conditions Surveys (EWCS) 2010 and 2015, and by Eurostat with the implementation of the EU-LFS ad hoc module on self-employment in 2017. All three surveys contain indicators aimed at capturing forms of dependency within self-employment.

The classifications developed within the Eurofound framework define dependent selfemployment starting from the methodological guidelines fixed by ICSE-93. Therefore, the indicators were formulated with the aim of identifying 'genuine' self-employment according to three criteria: having more than one client/costumer (or not having a dominant client); having the ability to hire or fire; and taking the main decisions about their own business. This means that the identification of dependency is derived by logic subtraction, 
since the lack of these criteria is a proxy of dependency. Consequently, the empirical works based on the EWCS data define a dependent self-employed as a solo self-employed who does not comply with one or two of the above indicators (Eurofound, 2013, 2017b; Williams \& Horodnic, 2018, 2019). This definition does not set a hierarchy between the three criteria, since the condition of dependency may be due either to a lack of economic independence or to a lack of operational independence, or both. Put differently, a dependent self-employed is defined by economic dependency or by operational dependency or both.

The operationalization of dependent self-employment implemented by Eurostat in the ad hoc module of the EU-LFS 2017 is instead based on two indicators of dependency: economic and organisational (Eurostat, 2018). The economic dependence - in line with Supiot's definition (1999) - is based on the main client approach. The operational dependency - labelled by Eurostat as 'organisational' dependency - is instead measured considering the level of control over working time. In this perspective, there is operational dependency when the working time is defined by the main client. According to the Eurostat framework, dependent self-employed are solo self-employed who worked during the last 12 months for only one client or for a dominant client and this client decides their working hours. Thus, both forms of dependency must be simultaneously present.

Comparing the methodologies developed by Eurofound and Eurostat, we can see that there is a general agreement about the use of the main client approach for the definition of economic dependency, but this is not the case for the operationalization of the different forms of operational dependency. While Eurofound focuses on the lack of autonomy over how to run the business, Eurostat focuses instead on the control of the working time (when to work). Moreover, in both surveys it is not clear how to combine economic and operational dependencies to identify dependent self-employment. Eurofound does not establish a prevalence rule between the different forms of dependency, while Eurostat fixes the rule that both forms of dependency must be present to identify dependent self-employment.

\section{Measuring Dependency Among the Solo Self-employed}

In the following, we analyse how the representation of self-employment changes according to different measures of economic dependency and operational dependency using both the EWCS 2015 and the EU-LFS ad hoc module 2017.

First, we compare the different operationalization of economic and operational dependency in the two surveys (see Table 1). Following the methodological indications developed by Eurofound and Eurostat, we operationalize operational dependency considering indicators of autonomy in both a) how to organise working tasks and activities; and b) deciding the working schedule (when to work).

The methodology proposed by Eurofound uses as operational dependency two indicators of autonomy on how to conduct the business and working tasks measured by the ability to hire employees and to take the main decisions about business activities (Eurofound, 2017). Eurostat, instead, does not include this information in the questionnaire of its ad hoc module. It is therefore not possible to reproduce the same operationalization procedure proposed by Eurofound. The only information about the level of autonomy on the organisation of work included in the EU-LFS refers to the worker's ability to influence the content and order of a job's tasks. Similar indicators are included in the EWCS. Thus, we propose an original operationalization of one of the forms of operational dependency based on the 
Table 1 Operationalization of different forms of dependency in EWCS (2015) and EU-LFS ad hoc module (2017)

Economic dependency

The identification of economic dependency is based on two questions:

"Q9d-Regarding your business, do you generally, have more than one client or customer?"

Options: Yes or No

"Q102-What proportion of revenue do you receive from your most important client?" (Options: 1) Less than 50 per cent; 2)50 to 75 per cent; 3)

More than 75 per cent)

There is economic dependency when a respondent mentions not having more than one client or more than $75 \%$ of revenue from the main one

\section{Time dependency}

The measure of the working time arrangement is based on the question:

"Q42-How are your working time arrangements set?", with four options:

1) they are set by the company/organisation with no possibility for change;

2) you can choose between several fixed working schedules determined by the company/organisation;

3) you can adapt your working hours within certain limits (e.g. flexitime); 4) your working hours are entirely determined by yourself

There is time dependency when the respondents answer that their working time arrangements are set by the company, or workers can choose or adapt within certain limits (options 1, 2 and 3)

\section{Task dependency}

Job autonomy is measured by two indicators that measure whether the respondent can control the order of tasks and the method of work

"Q54a-Are you able to choose or change. your order of tasks?" Options: Yes or No

"Q54b-Are you able to choose or change your methods of work" Options: Yes or No

There is task dependency when the respondents are not able to influence the order or the method of work
Economic dependency is measured by a categorical variable (MAINCLNT) that identifies the number and importance of clients in the last 12 months of self-employment

The answer options include: 1) no clients; 2) only one client; 3) 2-9 clients, but one was dominant; 4) 2-9 clients, and none was dominant; 5) more than 9 clients, but one was dominant; and 6) more than 9 clients, and none was dominant

A client is defined as dominant if they provide at least $75 \%$ of the income of self-employment in the last 12 months (Eurostat, 2018)

There is economic dependency when respondents have only one client or a dominant client over the last 12 months (options 2, 3 and 5)

Time dependency (WORKORG) is based on two questions:

"Q1_Workinghours Do you personally decide the start and end of the working day?" (Options Yes or $\mathrm{No}$ );

And if not, "Q2_Workinghours Who decides?" Three options 1) client/s; 2) any other party; 3) cannot say

These questions were asked to the self-employed who had at least one client during the last 12 months (or did not report the number of their clients)

There is time dependency when the respondents answer that their working day is decided by clients or by any other party

Note: to make the indicator more comparable with that calculated in the EWCS, we preferred a broader operationalization than the one suggested by Eurostat, which considers only the working time controlled by the main client (Eurostat, 2018)

Job autonomy is measured by two indicators that measure the ability to influence the content and the order of tasks in the main job. (Eurostat, 2018)

"Q1_Autonomy Do you have influence over the content of your tasks?" Options: Yes or No

"Q2_Autonomy Do you have influence over the order of your tasks?" Options: Yes or No

There is task dependency when the respondents are not able to influence the content $o r$ the order of tasks in the main job

Other indicators of operational dependency 
Table 1 (continued)

\begin{tabular}{ll}
\hline EWCS (2015) & EU-LFS ad hoc module (2017) \\
\hline Lack of autonomy in running the business: two & N/A \\
indicators on the ability to take the main decisions & \\
about business activities and to hire employees \\
"Q9a-Regarding your business, do you have the \\
authority to hire or dismiss employees?" Options: \\
Yes or No \\
"Q91e-I make the most important decisions on \\
how the business is run [To what extent do you \\
agree or disagree with the following statements?] \\
Options: Agree/Disagree \\
There is operational dependency when respond- \\
ents do not have the authority to hire or dismiss \\
employees or do not make the most important \\
decisions on how to run their business
\end{tabular}

lack of autonomy in deciding the order and content of job tasks, and we label this form of dependency as 'task dependency'.

The methodology proposed by Eurostat uses as operational dependency the level of control over working time. EWCS also contains a question that allows for identification of whether workers have complete control over their working time arrangement, or if it is fixed by others. Although the ways of collecting the information about the control of working schedule differ between the two surveys, it is possible to apply to EWCS the definition of dependent self-employment proposed by Eurostat. Specifically, this form of dependency can be referred to as 'time dependency'.

Thus, we first compare how the representation of self-employment changes according to different measures of economic dependency and operational dependency - composed of 'task' and 'time' dependency - in both EWCS and the EU-LFS ad hoc module. Moreover, using EWCS, we test how the measure of task dependency that we propose, based on the lack of autonomy in deciding the order and content of job tasks, overlaps with the previous measures of operational dependency adopted by Eurofound, which are based on the lack of autonomy in hiring employees and taking the main decisions about business activities (Eurofound, 2018; Williams \& Horodnic, 2018, 2019).

Second, we study how the representation of dependent self-employed workers changes by adopting a 'strict' or 'loose' definition of dependent self-employment based on how economic, time, and task dependency are combined. While according to the 'strict criterium', economic, time and task dependencies must be present simultaneously, the 'loose criterium' considers two out of three forms of dependency to be sufficient. Moreover, we compare how our 'strict' and 'loose' definitions of dependent self-employment overlap with the indicators of dependent self-employment developed by Eurostat (2018) and Eurofound (Williams \& Horodnic, 2018, 2019) (see Table 2).

Finally, by focusing on EWCS 2015 we move to a 'bottom-up' approach and use latent class analysis to examine whether there are similar patterns of dependency within (solo) self-employment (Lukac et al., 2019; Moortel \& Vanroelen, 2017; Van Aerden et al., 2014). In this analysis, we consider all five indicators of dependency developed in the current debate on dependent self-employment and available in the EWCS database: economic, time, and task dependency, as well as lack of autonomy in taking the main decisions about the business, and the impossibility of hiring employees. This allows for the identification of 
Table 2 Definitions of dependent self-employment employed in the analyses

\begin{tabular}{ll}
\hline Strict definition & $\begin{array}{c}\text { Dependent self-employed are solo self-employed who face simultaneously economic } \\
\text { dependency (work only for one client or a dominant client), time dependency and } \\
\text { task dependency (see Table1) }\end{array}$ \\
Lependent self-employed are solo self-employed who demonstrate at least two out \\
Depention \\
three of the following forms of dependency: economic dependency, time depend- \\
ency, or task dependency (see Table 1) \\
Dependent self-employed are solo self-employed who worked during the last \\
12 months for only one client or for a dominant client (economic dependency) \\
and this client decides their working hours (organizational dependency) (Eurostat, \\
2018) \\
Dependent self-employed are solo self-employed who demonstrate at least two out \\
three of the following forms of dependency: work only for one client or a dominant \\
client (economic dependency), lack of autonomy in hiring employees, and lack of \\
autonomy in taking the main decisions about their business activities (Eurofound, \\
2017; Williams \& Horodnic, 2018, 2019)
\end{tabular}

groups of solo self-employed workers who share similar patterns of dependency and compares them with the indicators of dependent self-employment based on the methodologies developed by Eurostat and Eurofound.

\section{Data and Methods}

The analysis is based on the EWCS 2015 (Eurofound, 2018) and on the 2017 ad hoc module on self-employment of the EU-LFS. The final sample includes self-defined solo selfemployed aged 15-74 in the EU-28. In the case of the EWCS, we selected only those who were reported to be 'at work' or 'at work but on parental leave' at the time of the interview. In the case of the EU-LFS ad hoc module, we considered those workers who in the reference week were working or not working but had a business or employment. The final samples include 3,499 solo self-employed workers in the EWCS 2015 and 57,304 in the EU-LFS ad hoc module 2017.

According to the methodologies proposed by Eurofound and Eurostat presented in the previous section, we tested different measures of economic and operational dependences and different definitions of dependent self-employment. Table 1 contains details on the operationalization of economic, time and task dependency, and other indicators of operational dependency available in the two databases, and Table 2 summarises the different definitions of dependent self-employment employed in the analyses.

Regarding the control variables in the comparison of the different forms of dependency and definitions of dependent self-employment, we considered the following: the type of economic activity in the main job (NACE 2, 1 digit); the type of occupation (ISCO-08); the years of permanence in the main job; and socio-demographics (sex, age classes, and the country of residence at the time of the interview).

Finally, focusing on EWCS 2015 - the survey that collects most information on forms of dependency in self-employment- we performed an exploratory latent class analysis to identify groups of solo self-employed workers who share similar patterns of dependency. This analysis uses all five dichotomous indicators discussed in the previous section that were deemed useful to detect forms of dependency: economic, time and task dependency, 
and lack of autonomy over how to conduct business, and in hiring employees. Different models were estimated, assuming the presence of one to five latent classes. The likelihoodratio $\left(\mathrm{G}^{2}\right)$ test (Goodman, 2002), the comparison of the BIC and AIC values of the models (Table 3), and the inspections of the different class solutions suggest that a four-class solution is the most suitable for the identification of different configurations of dependency.

\section{Results}

\subsection{Self-employment and Forms of Dependency}

Figure 1 shows the incidence of economic, time, and task dependency among the solo selfemployed in the EU-28 in both EWCS 2015 and EU-LFS 2017.

In the case of economic dependency, the estimates based on EWCS show that $26.1 \%$ of the solo self-employed are economically dependent, while in the EU-LFS economic dependency involves $20.3 \%$ of the solo self-employed. If those with zero clients were included, the estimate of the average economic dependence based on EU-LFS would be similar to that of EWCS. Moreover, according to the Eurostat methodological report (2018), it might be possible that there is an underestimation of this form of dependency due to the difficulty in understanding the term 'client' in some work contexts, as well as language translation problems (Eurostat, 2018). In some cases, such as taxi drivers and platform workers, it is for example difficult to establish who is the main client.

The major differences in the estimates between the two surveys concern the incidence of time dependency. The percentages based on EU-LFS show a limited incidence of time dependency: only $11.9 \%$ of the solo self-employed are time dependent in the EU-28. On the contrary, time dependency concerns $28.4 \%$ of the solo self-employed considered by EWCS, a proportion more than two times higher. This difference is partly due to the fact that in the EU-LFS the information on the level of autonomy on working schedule was not collected for the self-employed with zero clients in the past 12 months $(4.5 \%$ of the solo self-employed in EU-LFS). However, the different ways of collecting information on working time arrangements used in the two surveys provide distinct representations of the diffusion of time dependency among the solo self-employed.

By contrast, task dependency shows very similar average values for the EU-28 between the two surveys (19.8\% for EU-LFS versus $17.2 \%$ for EWCS) and the distribution across economic sectors is similar as well. However, the comparison of task

Table 3 Latent class models. Goodness-of-fit statistics. EWCS 2015

\begin{tabular}{|c|c|c|c|c|c|c|c|c|c|}
\hline \multicolumn{10}{|c|}{ Number of classes } \\
\hline \multicolumn{2}{|l|}{1} & \multicolumn{2}{|l|}{2} & \multicolumn{2}{|l|}{3} & \multicolumn{2}{|l|}{4} & \multicolumn{2}{|l|}{5} \\
\hline 11 (model) & -9044.6 & $1 l$ (model) & -8771.2 & 11 (model) & -8744.4 & 11 (model) & -8731.2 & 11 (model) & -8730.0 \\
\hline $\mathrm{df}$ & & df & 11 & $\mathrm{df}$ & 17 & df & 23 & df & 29 \\
\hline AIC & $18,099.3$ & AIC & $17,564.4$ & AIC & $17,522.8$ & AIC & $17,508.4$ & AIC & $17,518.0$ \\
\hline $\mathrm{BIC}$ & $18,130.1$ & BIC & $17,632.1$ & $\mathrm{BIC}$ & $17,627.54$ & $\mathrm{BIC}$ & $17,620.0$ & $\mathrm{BIC}$ & $17,696.6$ \\
\hline \multicolumn{10}{|c|}{ Likelihood ratio (Model vs. Satured Model) } \\
\hline $\operatorname{chi} 2(26)$ & 632.16 & $\operatorname{chi} 2(20)$ & 85.25 & $\operatorname{chi} 2(14)$ & 31.72 & $\operatorname{chi} 2(8)$ & 5.26 & $\operatorname{chi} 2(2)$ & 2.90 \\
\hline$p>\operatorname{chi} 2$ & 0.000 & $p>$ chi 2 & 0 & $p>\operatorname{chi} 2$ & 0.004 & $p p>\operatorname{chi} 2$ & 0.730 & $p>\operatorname{chi} 2$ & 0.234 \\
\hline
\end{tabular}




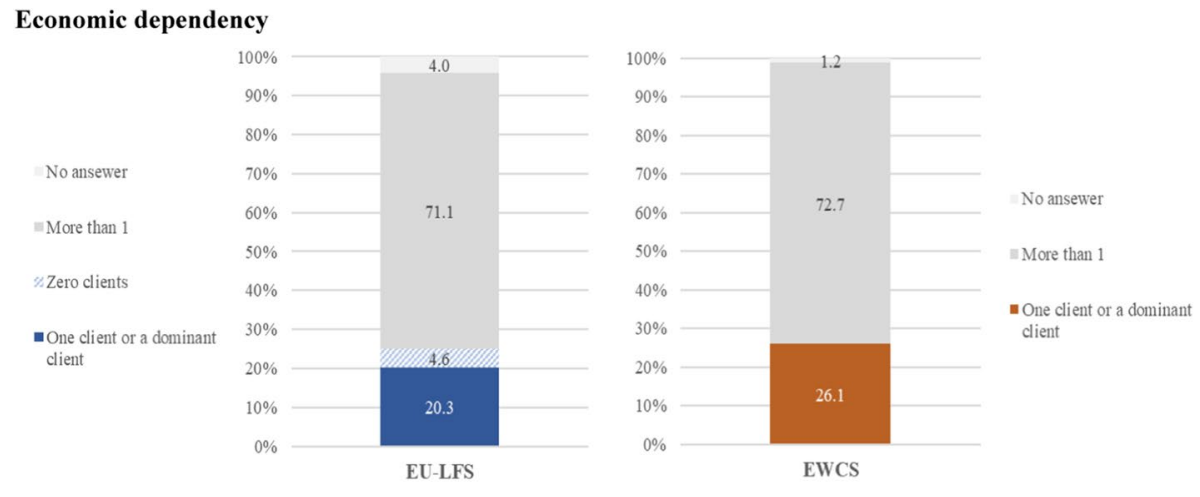

\section{Time dependency}
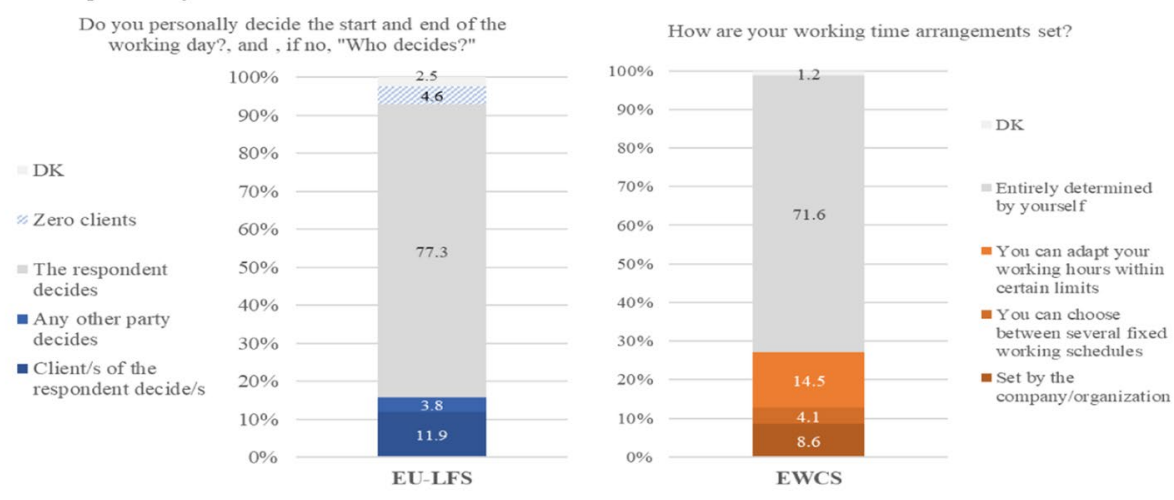

\section{Task dependency}

DK
Able to influence
both contents and
order
m Able to in fluence
contents, but not
order
m. Able to influence
order, but not
contents
Not able to influence
contents nor order
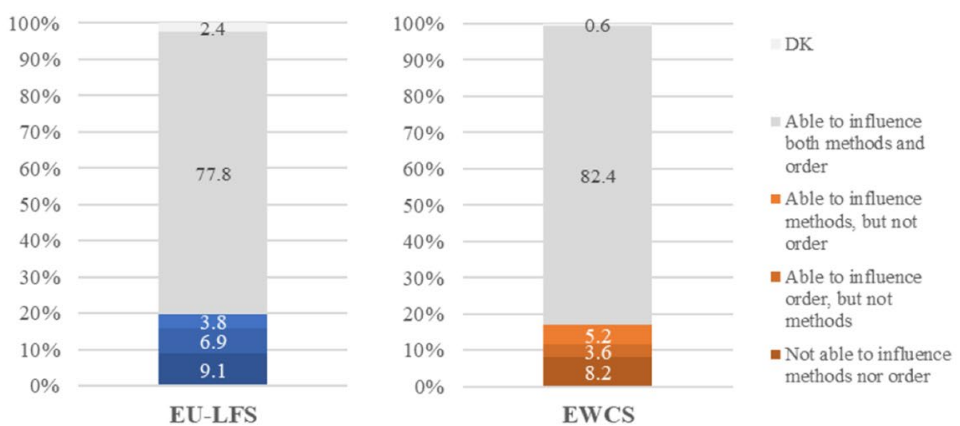

Fig. 1 Economic dependency, Time and Task dependency. Solo self-employed 15-74 in EU-LFS 2017 and EWCS 2015

dependency with other indicators on the lack of job autonomy available only in the EWCS database - i.e. the lack of autonomy in how to run a business or in hiring employees - shows a limited overlap between different indicators (Table 4). This suggests that the three indicators capture different forms of operational dependency over 
Table 4 Overlaps and mismatches between different indicators of operational dependency. EWCS 2015

\begin{tabular}{lcl}
\hline & \multicolumn{2}{l}{ Lack of autonomy in: } \\
\cline { 2 - 3 } & $\begin{array}{l}\text { Taking the main decisions about busi- } \\
\text { ness }(\%)\end{array}$ & $\begin{array}{l}\text { Hiring new } \\
\text { employees } \\
(\%)\end{array}$ \\
\hline \% on solo self-employed & 12.8 & 35.5 \\
Overlap with Time dependency & 6.6 & 13.4 \\
Mismatch with Time dependency & 27.9 & 37.8 \\
Overlap with Task dependency & 5.9 & 13.0 \\
Mismatch with Task dependency & 18.2 & 33.6 \\
\hline
\end{tabular}

how to manage one's own entrepreneurial activity and capture different types of autonomy and job control on the working activities.

To investigate how the different forms of dependency characterise solo self-employment in the two surveys, we studied the risk for the solo self-employed in experiencing each form of dependency, estimating logistic regressions that control for economic sector, type of occupation, years of permanence in the job, as well as for socio-demographics. Table 5 reports average marginal effects of the risk of experiencing economic, time, and task dependency by sector, type of occupation and duration in both surveys.

The models highlight that there are some economic activities that show in both surveys a higher risk of all forms of dependency, such as transportation and storage, information and communication, and arts and entertainment. Other economic activities are characterised by a greater presence of certain types of dependency and a limited presence of others. For example, in agriculture, the solo self-employed seem to be characterised mainly by economic dependency but less by time and task dependency.

Focusing on the type of occupation based on ISCO-08, the presence of different forms of dependency mainly concerns the solo self-employed in low-skilled occupations, which are on average low-paid and low-quality jobs. High-skilled solo self-employed positions (mainly among professionals in ICT, health services, education, art and entertainment, and engineering) show a high incidence of economic dependency, while task dependency is on average lower than in low- and medium-skilled self-employed positions.

Finally, considering the years of permanence in the main job, in line with the work of Böheim and Mühlberger (2009), the parameters estimated for the EU-LFS show that the relevance of all forms of dependency decreases with the permanence in the position. This suggests that the first period after the transition in a self-employed position is associated with higher risks of experiencing economic, time, and task dependencies, and the risks seem to be transitional, since they are less frequent for those who stay in the same position for a long time. Parameters estimated for EWCS show the same trend but are not statistically significant. Unfortunately, the lack of longitudinal information on previous job episodes does not allow for a proper test of the stability of different forms of dependency. However, previous analyses (see Böheim \& Mühlberger, 2009) stress the volatility of the indicator of economic dependency based on the number of clients, which tends to change rapidly over time, favouring errors in the measurements. 


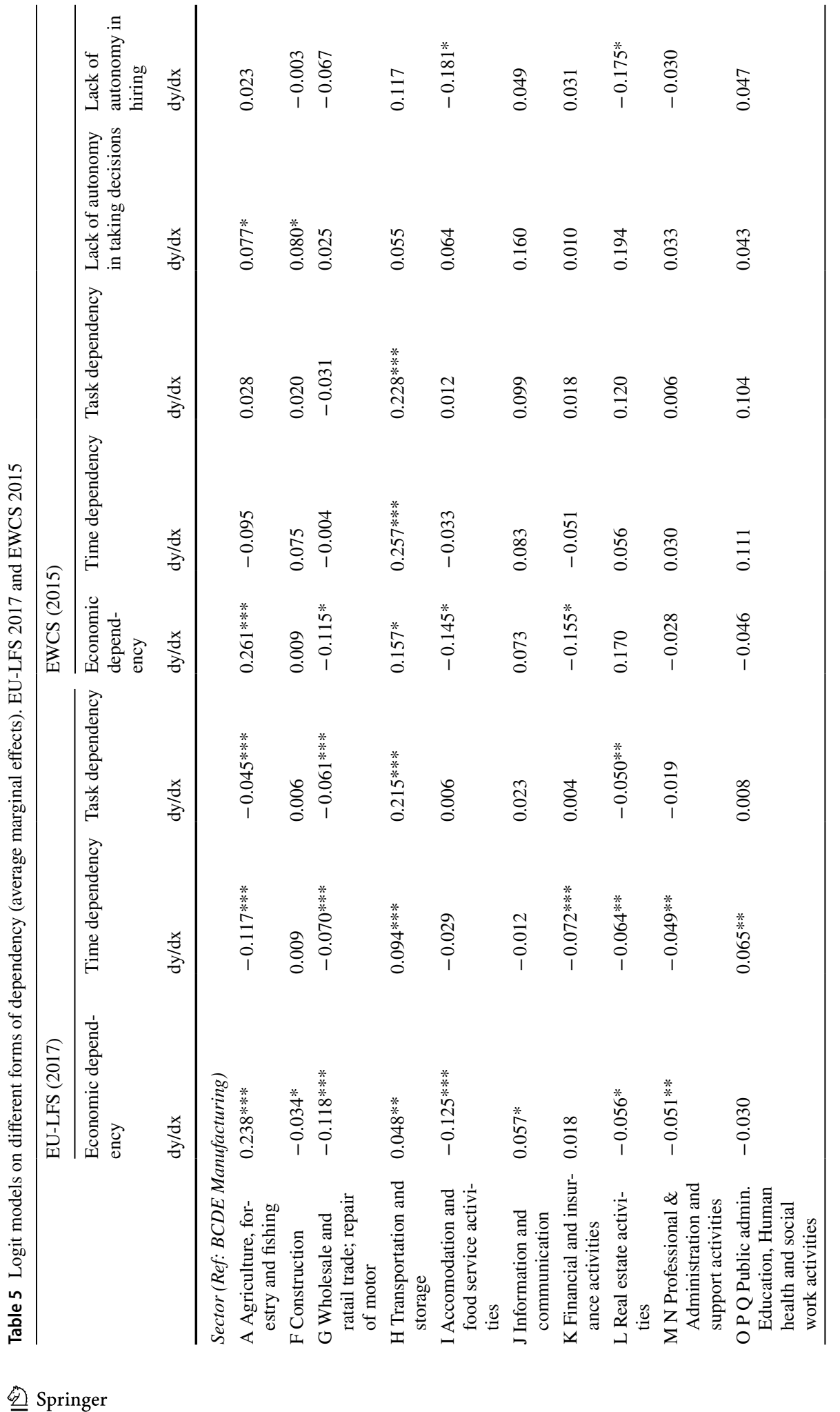




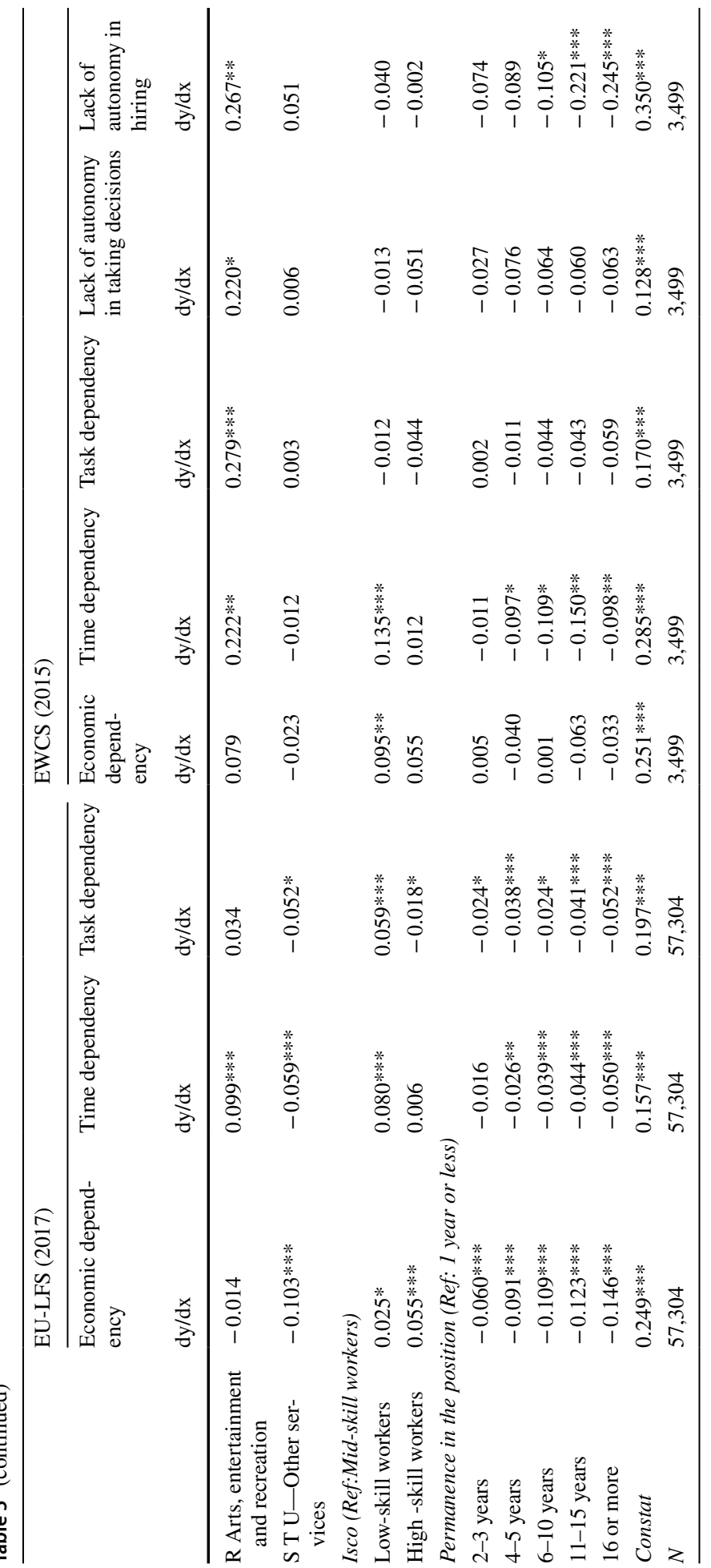




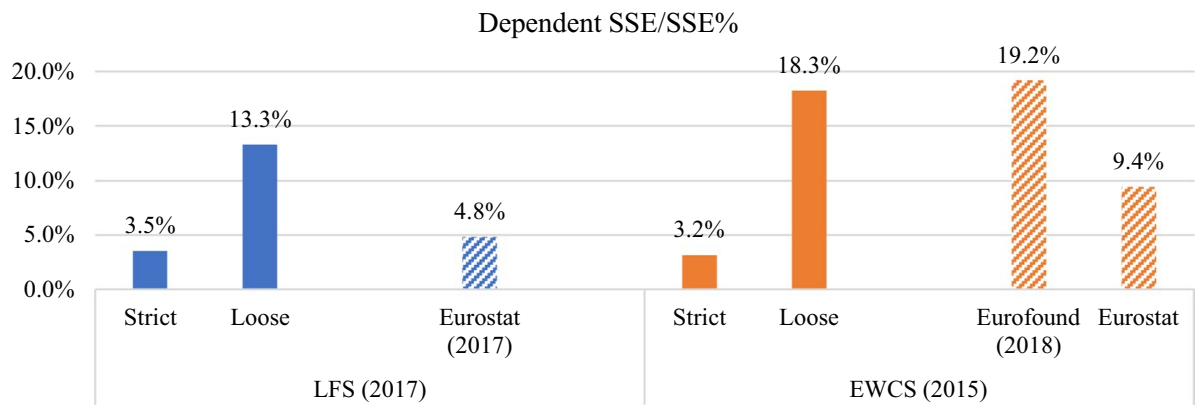

Fig. 2 Different definitions of Dependent self-employed (\% on solo self-employed) in EU-LFS 2017 and EWCS 2015

Table 6 Overlap and mismatch between different definitions of dependent self-employment. EU-LFS 2017 and EWCS 2015

Overlap on dependent self- Mismatch (\%) N employment (\%)

Eu-LFS, 2017

Strict versus Eurostat definition

3.2

4.8

Loose versus Eurostat definition

EWCS, 2015

Strict versus Eurostat definition

\section{3}

8.5

6.3

8.8

17.7

18.3
57,304

57,304

3,499

\section{2 'Strict' and 'Loose' Combinations of Different Forms of Dependency Within Self-employment}

The second step of the analysis focuses on how the representation of dependent selfemployment changes by adopting different strategies in combining the indicators of economic, time, and task dependency. Figure 2 summarizes the proportion of dependent selfemployed workers based on our 'strict' and 'loose' definitions, and a comparison with the estimation of dependent self-employment officially proposed by Eurostat (2018) and that proposed by Eurofound (Williams \& Horodnic, 2018, 2019) (Table 2).

Only $3.5 \%$ of the solo self-employed in the EU-LFS and 3.2\% in EWCS share economic, time, and task dependency simultaneously. The proportion of dependent self-employed workers increases markedly by adopting a loose definition, especially in the case of EWCS. According to our loose definition, indeed, the proportion of dependent self-employment reaches $13.3 \%$ in the EU-LFS and $18.3 \%$ in the EWCS. The differences between the estimates based on EWCS and EU-LFS are mainly due to the different levels of time dependency measured in the two surveys.

Table 6 shows a comparison between our 'loose' and 'strict' definitions of dependent self-employment and the Eurofound and Eurostat definitions in both surveys. The main result is that there is little overlap between the different measurements. In particular, 
with regard to Eurofound, while apparently the marginal distributions of the two indicators are similar (18.3\% vs $19.1 \%$ ) (Fig. 2), their cross-tabulation shows that $16.5 \%$ of cases are mismatched, while only $10.4 \%$ of cases are considered dependent self-employment according to both definitions.

The logit model of the probability of mismatch between our 'loose' definition and the Eurofound definition of dependent self-employment highlights that the risk of mismatch is particularly high for the solo self-employed in the transportation and storage sectors, real estate, agriculture, construction, and arts and entertainment (Fig. 3) as well as in low-skilled occupations.

These mismatches in the identification of dependent self-employment between the two methodologies are due to the differences in the operationalization of the operational dependency, that is to say time and task dependency versus lack of autonomy in taking decisions and hiring employees. As shown in the models in Table 3, the self-employed in transportation and storage suffer more in terms of time dependency but report high autonomy in making the main decisions about their business. Self-employed workers in the arts, entertainment and recreation suffer from both high levels of time and task dependency and a lack of autonomy in hiring employees, but there is little overlap between the different indicators. Thus, different operationalization strategies lead to significant differences in the identification of dependent self-employment based on the same data source.

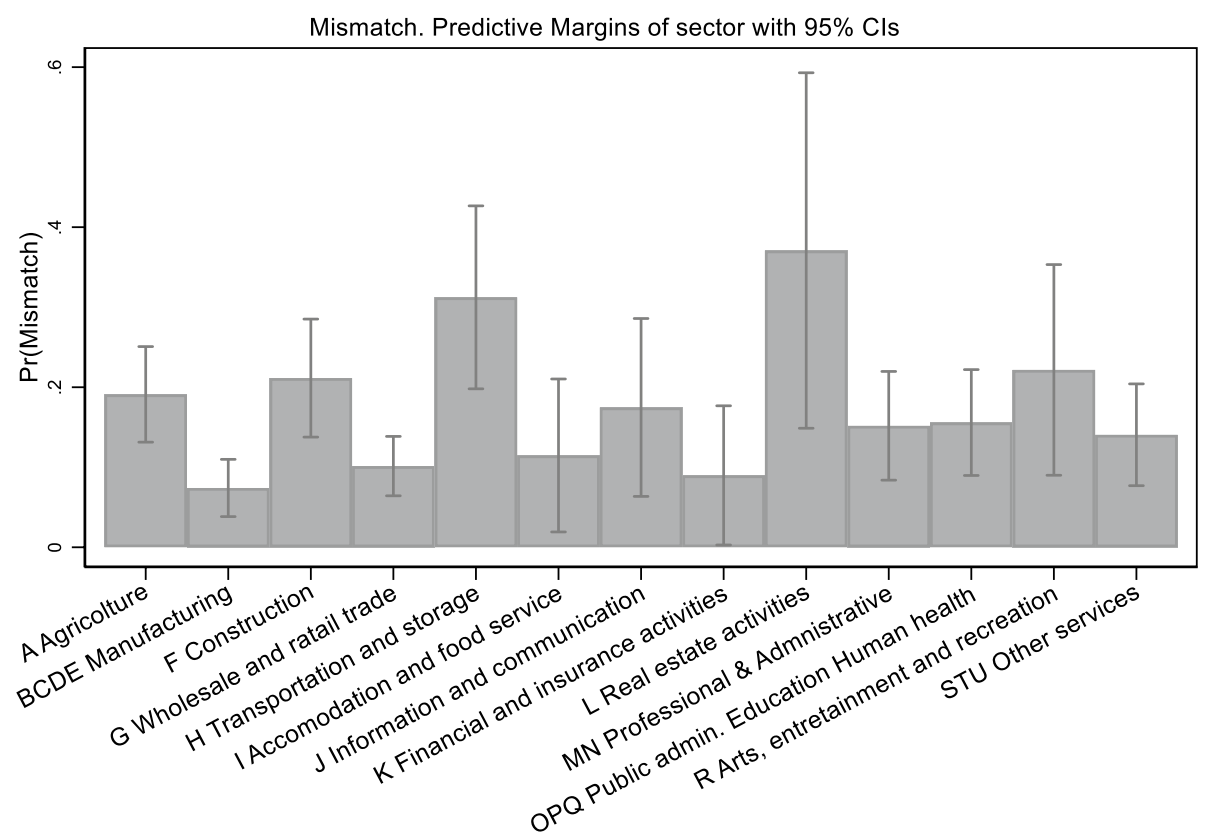

Fig. 3 Mismatch between Loose and Eurofound definitions of dependent self-employment. Predictive margins of sector with 95\% CIs. EWCS 2015. Note: Predictive margins based on a logit model on the probability of mismatch between Loose and Eurofound definition of dependent self employment. Control variables: isco, permanence in the job position, sex, age, and country of residence (Appendix, Table 7) 


\subsection{Latent Class Analysis: Emerging Patterns of Dependency}

In this last section, we move to a bottom-up approach with the aim of identifying different groups of solo self-employed workers according to their experience of dependency. Different from the previous analysis, we do not set up a threshold between genuine and dependent self-employment; instead, we look for an empirical typology of different patterns of dependency. Figure 4 summarises the predicted probabilities of the different configurations of dependency for the four classes identified by the latent class model. Class 1 consists of self-employed workers with very low or null levels of dependency on all five indicators considered. This class identifies 'genuine self-employed' and corresponds to $54.5 \%$ of the solo self-employed in the EWCS sample. This means that almost $45.5 \%$ of the selfemployed are attributed to classes that are affected by some forms of dependency, mainly operational dependency. More precisely, Class 2 is composed of self-employed workers who are mainly characterised by time dependency usually combined with task or economic dependency, representing almost $21.3 \%$ of the solo self-employed. Class 3 corresponds to solo self-employed workers who combine the lack of autonomy in hiring employees mainly with economic or time dependency, comprising almost $13 \%$ of the sample. Finally, Class 4 collects positions which share high levels of both economic and operational dependency and represents $11.2 \%$ of the solo self-employed in the sample.

The study of the differences between the four classes based on a multinomial logistic model (which controls for sector, type of occupation, permanence in the position, and socio-demographics) shows that the prevalence of different patterns of dependency varies consistently across sectors (Fig. 5). In particular, transportation and storage, communication and information, education and human health, and arts and entertainment show a higher probability of being in Classes 2, 3 or 4 . Thus, the solo self-employed in these
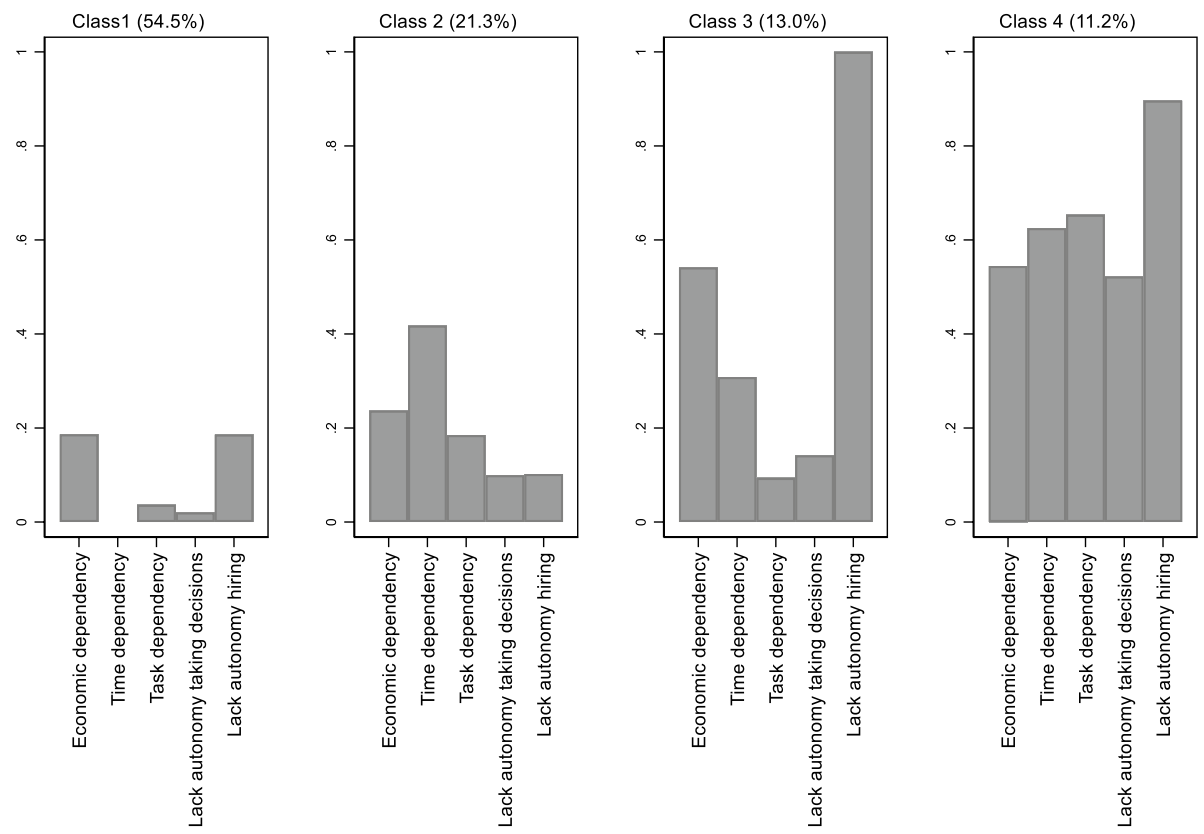

Fig. 4 Latent class analysis: predictive margins and class distribution (\%). EWCS 2015 
Adjusted Predictions of sector
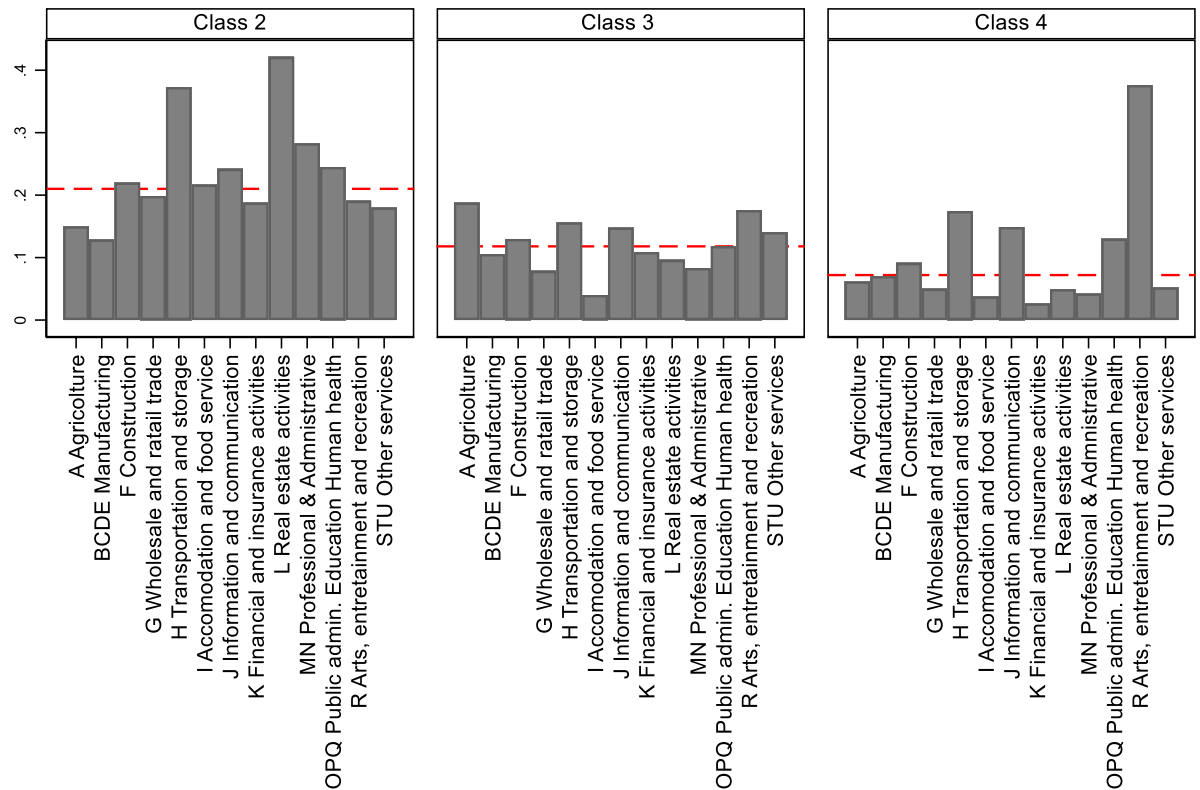

Fig. 5 Typology of the patterns of dependency within solo self-employment by sector (Adjusted predictions). EWCS 2015. Note: Adjusted predictions based of a multinomial logit on the typology of dependency patterns in self-employment. Control variables: isco (1 digit), years of permanence in the job position, sex, age classes, and country of residence (Appendix, Table 8). Horizontal dash line: average predictive margins of each class

sectors are more likely to experience multiple conditions of dependency. But while for the first three sectors the probability of being in Class 2 prevails (i.e. to share working arrangements more related to time dependency in combination with economic and task dependency), the arts, entertainment and recreation sector prevails in Class 4, which is defined by the simultaneous presence of all types of dependency.

\section{Discussion and Conclusion}

The main aim of this work is to contribute to debates on the classification of the emerging work arrangements within self-employment, including platform work, which are deeply transforming employment relations. In particular, we have assessed how different operationalizations of economic and operational dependency within self-employment affect the identification and representation of dependent self-employment in different economic sectors.

Our analysis indicates that there is limited overlap between economic and operational dependency and that different methodologies lead to very different representations of dependent self-employment. The small overlap between different forms of dependency could be the result of two different circumstances. First, it could be the case that it is 
relatively rare that a self-employed simultaneously experiences both economic and a specific form of operational dependency. Second, the indicators considered may not be sufficient for adequately capturing dependency (ILO, 2018a). The analysis developed in this work supports both options.

An open issue related to the debate on dependent self-employment concerns whether the self-employed who do not report economic dependency can be classified as dependent selfemployed. The analyses presented in this work suggest that there are several cases where dependent self-employment is mainly due to the prevalence of operational dependency. For instance, jobs performed in the platform economy often represent situations in which the economic dependency based on the main client approach is not helpful for understanding how work relations are structured (De Stefano \& Aloisi, 2018). Moreover, the latent class analysis conducted in this work shows that three out of four classes identify patterns of dependency where the prevalence of a form of operational dependency (mainly the lack of autonomy in hiring or time dependency) is usually combined with other forms of operational and/or economic dependency. In relation to this, it is worth noting that the operationalization strategy implemented by Eurostat is quite restrictive in identifying concrete conditions of dependent self-employment, since it considers the role of economic dependency as a conditio sine qua non and combines it with (only) a single form of operational dependency (i.e. time dependency). On the contrary, the more inclusive methodology proposed by Eurofound allows higher levels of dependency within self-employment to be captured.

At present, the different indicators of operational dependency considered in our 'loose' definition and in the Eurofound definition of dependent self-employment lead to numerous cases of misclassification between the two methodologies, especially in economic sectors that are more exposed to the development of ambiguous working conditions between employment and self-employment, such as transportation and storage, construction, real estate, and arts and entertainment. The latent class analysis carried out on the five indicators of economic and operational dependencies has identified four patterns of dependency in self-employment, revealing configurations of different forms of dependency that are broader and do not overlap with those identified following the 'top-down' approaches. In particular, three classes are mainly defined by the prevalence of the lack of autonomy in hiring employees and by time dependency (variously combined with one or more of the other forms of dependency) which are not considered by top-down approaches.

These results suggest that the first step to improve the measurement of dependent selfemployment is to develop a more accurate classification of the different forms of dependency in self-employment, widening the indicators considered and overcoming a narrow focus on economic dependency. In this direction, a criterium to improve the indicators of dependency can be derived from the comparative labour law debate on the detection of forms of subordination. Recent works (see Digennaro, 2020) have indicated that when a self-employed position is defined by lack of power to direct someone else's work or is subject to hierarchical control from the organisation of the employer or is in a condition of economic dependency, then this position is close to that of an employee. Dependent self-employment is therefore identified by the presence of one of these conditions. The five indicators employed in the latent class analysis fit all the three mentioned conditions and should then all be systematically collected for the identification of dependent self-employment. 
However, it remains an open issue whether there are other dimensions which could allow a more refined identification of the patterns of dependency within self-employment, namely in terms of operational dependency. Both economic and labour law debates assume that employees act under the direction of the employer as regards their freedom to choose the time, content, and place of their work (without sharing business risks with the employer) (Countouris \& De Stefano, 2019; Digennaro, 2020). Thus, a comprehensive operationalization of dependent self-employment should include at least three areas of operational dependency in order to identify hierarchical control (or lack of autonomy) on when, where and how to work. In this regard, a limitation in methodologies analysed in this work is the lack of indicators of operational dependency able to capture the lack of autonomy about the workplace. Daily work carried out by a selfemployed at the premises of someone else's organisation, as well as who owns working equipment and devices, could be a further valid indicator of operational dependency and of the existence of a situation of subordination. Unfortunately, both the EWCS and the EU-LFS either do not include any information related to the workplace or such information is collected only for employees.

In conclusion, in the last twenty years there has been a progressive refinement of the definitions of the conditions that characterise dependent self-employment, which nowadays concerns people working both offline and through online platforms. However, these theoretical efforts are still encountering difficulties on the empirical level of data collection. Official statistics and labour force surveys still do not provide a robust measurement of this phenomenon, as well as an adequate availability of indicators able to detect and monitor the different patterns of dependency that are affecting and segmenting self-employment. The implementation of a consistent operationalisation of the category of dependent self-employed workers (or 'dependent contractors') requires accurate measurements of its constitutive dimensions, that is to say the different forms of economic and operational dependencies. While the identification of economic dependency based on the main client approach is a relatively consolidated practice - even if information on economic dependency is not collected systematically in official labour force surveys - the identification of the different conditions of operational dependency is still at a pilot stage. Regarding future research perspectives, the analyses presented in this article therefore show the urgency of developing comprehensive and suitable measurements of operational dependency. In this direction, at least three dimensions should be considered to capture different forms of hierarchical control (or lack of autonomy) on when, where, and how to work.

\section{Appendix}

See Tables 7 and 8. 
Table 7 Mismatch between loose and Eurofound definition. Logistic regression. EWCS 2015

Coef.

Sector(Ref: BCDE Manufacturing)

A Agriculture, forestry and fishing

F Construction

$\mathrm{G}$ Wholesale and ratail trade; repair of motor

0.427

$\mathrm{H}$ Transportation and storage

$1.805 * * *$

I Accomodation and food service activities

0.584

$\mathrm{J}$ Information and communication

$0.996 * *$

K Financial and insurance activities

0.190

L Real estate activities

$2.048 * * *$

M N Professional \& Administration and support activities

$0.806 * * *$

O P Q Public admin. Education, Human health and social work activities

$\mathrm{R}$ Arts, entertainment and recreation

S T U-Other services

Isco(Ref:Mid-skill workers)

Low-skill workers

High -skill workers

0.104

Permanence in the position( Ref: 1 year or less)

2-3 years

$4-5$ years

$-0.297$

6-10 years

$-0.349$

11-15 years

$-0.133$

16 or more

Sex (Ref: Men)

Women

Age classes(Ref: 15-29)

30-44

45-59

60-74

0.120

Country (Ref: Belgium)

Bulgaria

Czech Republic

$-0.608 * * *$

Denmark

$-0.395 * * *$

Germany

Estonia

Greece

$-0.148$

Spain

$-0.074$

France

$-0.012$

Ireland

$0.261 * *$

Italy

$-0.960 * * *$

Cyprus

0.120

Latvia

Lithuania 
Table 7 (continued)

Coef.

Malta

$-0.444 * * *$

Netherlands

$-0.413 * * *$

Austria

0.153

Poland

0.150

Portugal

$-0.163$

Romania

$0.706^{* * *}$

Slovenia

$-0.109$

Slovakia

0.119

Finland

0.286 *

Sweden

$-0.094$

United Kingdom

0.103

Croatia

Constant

$-2.879 * * *$

$* * * p<0.001 ; * * p<0.01 ; * p<0.05$ 
Table 8 Typology of dependency within Solo Self-Employment. Multinomial logit (Ref: Class 1). EWCS 2015

$\begin{array}{lll}\text { Class 2 } & \text { Class 3 } & \text { Class 4 } \\ \mathrm{b} & \mathrm{b} & \mathrm{b}\end{array}$

Sector(Ref: BCDE Manufacturing)

\begin{tabular}{|c|c|c|c|}
\hline A Agricolture & 0.298 & 0.724 & 0.017 \\
\hline F Construction & $0.752 *$ & $0.425^{* *}$ & 0.480 \\
\hline G Wholesale and ratail & $0.466^{*}$ & -0.261 & -0.304 \\
\hline H Transportation and storage & $1.915^{* * *}$ & $1.246^{* *}$ & $1.762 * * *$ \\
\hline I Accomodation and food & 0.505 & -0.983 & -0.635 \\
\hline $\mathrm{J}$ Information and communication & $1.041 * *$ & 0.748 & $1.160 *$ \\
\hline K Financial and insurance & 0.404 & 0.057 & -0.943 \\
\hline L Real estate activit & $1.658 * *$ & 0.380 & 0.120 \\
\hline MN Professional \& Admin & $0.948 * * *$ & -0.075 & -0.348 \\
\hline OPQ Public admin. Edu & $0.960 * * *$ & 0.432 & $0.932 * *$ \\
\hline R Arts, entretainment & $1.389 * * *$ & $1.507 * * *$ & $2.672 * * *$ \\
\hline STU Other services & 0.438 & 0.391 & -0.193 \\
\hline \multicolumn{4}{|l|}{ Isco(Ref:Mid-skill workers) } \\
\hline Low-skill workers & 0.395 & 0.525 & -0.042 \\
\hline High -skill workers & -0.324 & $0.486^{*}$ & $-0.467 *$ \\
\hline \multicolumn{4}{|c|}{ Permanence in the position( Ref: 1 year or less) } \\
\hline $2-3$ years & 0.074 & -0.222 & -0.429 \\
\hline $4-5$ years & -0.259 & $-0.896^{*}$ & -0.607 \\
\hline $6-10$ years & $-0.324^{*}$ & -0.622 & -0.813 \\
\hline $11-15$ years & -0.115 & -0.956 & $-1.155^{* *}$ \\
\hline 16 or more & 0.025 & -0.851 & $-1.371 * *$ \\
\hline \multicolumn{4}{|l|}{$\operatorname{Sex}(\operatorname{Ref}:$ Men $)$} \\
\hline Women & -0.141 & $0.396 *$ & 0.101 \\
\hline \multicolumn{4}{|l|}{ Age classes(Ref: 15-29) } \\
\hline $30-44$ & -0.246 & -0.088 & -0.475 \\
\hline $45-59$ & -0.098 & -0.055 & -0.514 \\
\hline $60-74$ & -0.493 & -0.123 & -0.445 \\
\hline \multicolumn{4}{|l|}{ Country (Ref: Belgium) } \\
\hline Bulgaria & $-0.673 * * *$ & $0.704 * * *$ & $-0.473 * *$ \\
\hline Czech Republic & $-0.191 *$ & -0.061 & $0.772 * *$ \\
\hline Denmark & $0.194 * * *$ & $-0.193 * *$ & $-13.446^{* * *}$ \\
\hline Germany & $0.658 * * *$ & $0.634 * * *$ & $1.023 * * *$ \\
\hline Estonia & $1.013 * * *$ & $1.483 * * *$ & $0.858 * * *$ \\
\hline Greece & $0.424 * * *$ & 0.039 & $-0.558 * * *$ \\
\hline Spain & $0.471^{* * *}$ & $0.355^{* * *}$ & $0.288 * *$ \\
\hline France & -0.132 & $0.568 * * *$ & $0.218^{* * *}$ \\
\hline Ireland & $0.627 * * *$ & $0.194 * *$ & $0.449 * * *$ \\
\hline Italy & $-0.527 * * *$ & $0.434 * * *$ & -0.090 \\
\hline Cyprus & $0.304 * * *$ & $0.872 * * *$ & $-0.288^{*}$ \\
\hline Latvia & 0.131 & $1.218^{* * *}$ & $0.977 * * *$ \\
\hline Lithuania & $0.316^{* *}$ & $1.567 * * *$ & $1.636^{* * * *}$ \\
\hline Luxembourg & 0.093 & $0.604 * *$ & -0.110 \\
\hline
\end{tabular}


Table 8 (continued)

\begin{tabular}{llll}
\hline & $\begin{array}{l}\text { Class } 2 \\
\mathrm{~b}\end{array}$ & $\begin{array}{l}\text { Class } 3 \\
\mathrm{~b}\end{array}$ & $\begin{array}{l}\text { Class } 4 \\
\mathrm{~b}\end{array}$ \\
\hline Hungary & $0.775^{* * *}$ & 0.178 & $0.403^{*}$ \\
Malta & $-0.840^{* * *}$ & $0.552^{* * *}$ & $-1.880^{* * *}$ \\
Netherlands & 0.068 & $-0.240^{*}$ & $-1.457^{* * *}$ \\
Austria & $0.318^{* * *}$ & $0.924^{* * *}$ & $0.235^{*}$ \\
Poland & $0.563^{* * *}$ & $0.457^{* * *}$ & $1.119^{* * * *}$ \\
Portugal & $-0.760^{* * *}$ & $0.595^{* *}$ & 0.260 \\
Romania & -0.187 & $2.147^{* * *}$ & $1.635^{* * *}$ \\
Slovenia & $0.471^{* * *}$ & $-0.248^{* * *}$ & 0.284 \\
Slovakia & $0.180^{*}$ & $2.039^{* * *}$ & $1.272^{* * *}$ \\
Finland & $0.940^{* * *}$ & $0.251^{*}$ & $-0.510^{* *}$ \\
Sweden & $0.542^{* * *}$ & $0.268^{* *}$ & $-13.392^{* * *}$ \\
United Kingdom & $-0.093^{* *}$ & $1.405^{* * *}$ & $1.220^{* * * *}$ \\
Croatia & $0.366^{* * *}$ & $1.467 * * *$ & -0.405 \\
Constant & $-1.379^{* * *}$ & $-2.353^{* * *}$ & $-1.069^{* *}$ \\
\hline
\end{tabular}

$* * * p<0.001 ; * * p<0.01 ; * p<0.05$

Funding Open access funding provided by Università degli Studi di Milano within the CRUI-CARE Agreement. This work was supported by the European Research Council (ERC) under the European Union's Horizon 2020 research and innovation programme (Grant Agreement No. 715950).

Availability of Data and Material This paper is based on data from Eurostat, EU Labour Force Survey (2017 - Ad Hoc Module on Self-Employment) and on the 6th wave of the European Working Condition survey (2015). The European Working Condition 2015 data that support the findings of this study are available in UK Data Service at https://doi.org/10.5255/UKDA-SN-8098-4, reference number SN: 8098. The responsibility for all conclusions drawn from the data lies entirely with the authors.

Code Availability Not applicable.

\section{Declarations}

Conflict of interest The authors declared that they have no conflicts of interest.

Open Access This article is licensed under a Creative Commons Attribution 4.0 International License, which permits use, sharing, adaptation, distribution and reproduction in any medium or format, as long as you give appropriate credit to the original author(s) and the source, provide a link to the Creative Commons licence, and indicate if changes were made. The images or other third party material in this article are included in the article's Creative Commons licence, unless indicated otherwise in a credit line to the material. If material is not included in the article's Creative Commons licence and your intended use is not permitted by statutory regulation or exceeds the permitted use, you will need to obtain permission directly from the copyright holder. To view a copy of this licence, visit http://creativecommons.org/licenses/by/4.0/.

\section{References}

Arruñada, B., González-Díaz, M., \& Fernández, A. (2004). Determinants of organizational form: Transaction costs and institutions in the European trucking industry. Industrial and Corporate Change, 13(6), 867-882. https://doi.org/10.1093/icc/dth033 
Azaïs, C., Dieuaide, P., \& Kesselman, D. (2017). Zone grise d'emploi, pouvoir de l'employeur et espace public: Une illustration à partir du cas Uber. Relations Industrielles/industrial Relations, 72(3), 433-456.

Behrendt, C., Nguyen, Q. A., \& Rani, U. (2019). Social protection systems and the future of work: Ensuring social security for digital platform workers. International Social Security Review, 72(3), 17-41. https:// doi.org/10.1111/issr. 12212

Bisom-Rapp, S., \& Coiquaud, U. (2017). The role of the state towards the grey zone of employment: Eyes on Canada and the United States. Revue Interventions Économiques. Papers in Political Economy, (58).

Böheim, R., \& Mühlberger, U. (2009). Dependent self-employment: Workers between employment and selfemployment in the UK. Zeitschrift Für ArbeitsmarktForschung/Journal for Labour Market Research, 42(2), 182-195. https://doi.org/10.1007/s12651-009-0014-X

Borghi, P., Murgia, A., Mondon-Navazo, M., \& Mezihorak, P. (2021). Mind the gap between discourses and practices: Platform workers' representation in France and Italy. European Journal of Industrial Relations. https://doi.org/10.1177/09596801211004268.

Burke, A. (2015). The Handbook of Research on Freelancing and Self-Employment. (A. Burke, Ed.) Journal of Teacher Education (Vol. 13). Dublin: Senate Hall Academic Publishing.

Cherry, M. A., \& Aloisi, A. (2016). Dependent Contractors in the Gig Economy: A Comparative Approach. American University Law Review, 66. https://heinonline.org/HOL/Page?handle=hein.journals/aulr66\& $\mathrm{id}=663 \&$ div $=21 \&$ collection $=$ journals. Accessed 22 April 2020

Cieślik, J., \& Dvoulety, O. (2019). Segmentation of the population of the solo self-employed. International Review of Entrepreneurship, 17(3), 281.

Conen, W., \& Schippers, J. (2019). Self-employment: Between freedom and insecurity. In W. Conen \& J. Schippers (Eds.), Self-Employment as Precarious Work (pp. 1-22). Edward Elgar Publishing.

Countouris, N., \& De Stefano, V. (2019). New trade union strategies for new forms of employment. European Trade Union Council.

De Stefano, V., \& Aloisi, A. (2018). Employment and working conditions of selected types of platform work. National context analysis: Italy. Publications Office of the European Union.

Digennaro, P. (2020). Subordination or subjection? A study about the dividing line between subordinate work and self-employment in six European legal systems. Labour \& Law Issues, 6(1), 1-47. https:// doi.org/10.6092/issn.2421-2695/11254

Eichhorst, W., Braga, M., Famira-Mühlberger, U., Gerard, M., Horvath, T., Kahanec, M., et al. (2013). Social protection rights of economically dependent self-employed workers, 126. http://www.europ arl.europa.eu/studies

Emmenegger, P., Häusermann, S., Palier, B., \& Seeleib-Kaiser, M. (2012). How Rich Countries Cope with Deindustrialization. In The Age of Dualization (pp. 304-320). Oxford University Press. https:// doi.org/10.1093/acprof:oso/9780199797899.003.0013

Eurofound (2012). Fifth Eurofound Working Conditions Survey. Luxembourg: Publications Office of the European Union. https://www.eurofound.europa.eu/sites/default/files/ef_publication/field_ef_ document/ef1182en.pdf

Eurofound (2013). Self-employed or not self-employed? Working conditions of 'economically dependent workers.' www.eurofound.europa.eu. Accessed 22 February 2020

Eurofound. (2017). Exploring self-employment in the European Union. Publications Office of the European Union. https://doi.org/10.2806/651917TJ-01-17-770-EN-N

Eurostat. (2018). Labour Force Survey (LFS) ad-hoc module 2017 on the self-employed persons. Assessment Report. https://doi.org/10.2785/284

Frade, C., \& Darmon, I. (2005). New modes of business organization and precarious employment: Towards the recommodification of labour? Journal of European Social Policy, 15(2), 107-121. https://doi.org/10.1177/0958928705051509

Goodman, L. A. (2002). Latent class analysis: The empirical study of latent types, latent variables, and latent structures. In J. A. Hagenaars \& A. L. McCutcheon (Eds.), Applied Latent Class Analysis (pp. 3-55). Cambridge University Press.

Goos, M., Manning, A., \& Salomons, A. (2014). Explaining job polarization: Routine-biased technological change and offshoring. American Economic Review, 104(8), 2509-2526. https://doi.org/10. 1257/aer.104.8.2509

Howcroft, D., \& Bergvall-Kåreborn, B. (2019). A typology of crowdwork platforms. Work, Employment and Society, 33(1), 21-38.

ILO (1993) Resolution concerning the International Classification of Status in Employment (ICSE). http://www.ilo.org/global/statistics-and-databases/standards-and-guidelines/resolutions-adopt 
ed-by-international-conferences-of-labour-statisticians/WCMS_087562/lang--en/index.htm. Accessed 14 December 2020

ILO (2003). Repori I. General report. Seventeenth International Conference of Labour Statisticians. https://doi.org/10.1017/CBO9781139095686.002. Accessed 14 December 2020

ILO. (2018a). Resolution concerning statistics on work relationships. http://www.ilo.org/wcmsp5/ groups/public/---dgreports/---stat/documents/meetingdocument/wcms_619086.pdf. Accessed 14 December 2020

ILO. (2018b). Room Document: 6. Statistical definition and measurement of dependent "self-employed" workers. Rationale for the proposal for a statistical category of dependent contractors. https://ilost at.ilo.org/resources/methods/icls/icls-documents/. Accessed 14 December 2020

ILO. (2018c). Room Document 10. Testing of proposals for a revised International Classification of Status in Employment. https://ilostat.ilo.org/resources/methods/icls/icls-documents/. Accessed 14 December 2020

Kaine, S., \& Josserand, E. (2019). The organisation and experience of work in the gig economy. Journal of Industrial Relations, 1-23.

Kautonen, T., Down, S., Welter, F., Vainio, P., Palmroos, J., Althoff, K., \& Kolb, S. (2010). Involuntary self-employment as a public policy issue: A cross-country European review. International Journal of Entrepreneurial Behaviour \& Research, 16(2), 1355-2554. https://doi.org/10.1108/1355255101 1027002

Kautonen, T., \& Kibler, E. (2016). The 'grey area' between employment and self-employment: Implications for official statistics. Outlook Report. Power from Statistics. https://ec.europa.eu/eurostat/ cros/powerfromstatistics/OR/PfS-OutlookReport-Kautonen_Kibler.pdf

Kurer, T., \& Palier, B. (2019). Shrinking and shouting: The political revolt of the declining middle in times of employment polarization. Research and Politics. https://doi.org/10.1177/2053168019 831164

Lindbeck, A., \& Snower, D. J. (2001). Insiders versus outsiders. Journal of Economic Perspectives, 15(1), 165-188. https://doi.org/10.1257/jep.15.1.165

Lukac, M., Doerflinger, N., \& Pulignano, V. (2019). Developing a cross-national comparative framework for studying labour market segmentation: Measurement equivalence with latent class analysis. Social Indicators Research, 145(1), 233-255. https://doi.org/10.1007/s11205-019-02101-3

Meyer, B. (2019). Financialization, technological change, and trade union decline. Socio-Economic Review. https://doi.org/10.1093/ser/mwx022

Moortel, D., \& Vanroelen, C. (2017). Classifying self-employment and creating an empirical typology. Technical Report. Dublin: European Foundation for the Improvement of Living and Working Conditions, https://www.eurofound.europa.eu/sites/default/files/wpef17002.pdf.

Muehlberger, U. (2007). Hierarchical forms of outsourcing and the creation of dependency. Organization Studies, 28(5), 709-727. https://doi.org/10.1177/0170840607078119

Muehlberger, U., \& Pasqua, S. (2009). Workers on the border between employment and self-employment. Review of Social Economy, 67(2), 201-228. https://doi.org/10.1080/00346760701875215

Murgia, A., Bozzon, R., Digennaro, P., Mezihorak, P., Mondon-Navazo, M., \& Borghi, P. (2020). Hybrid areas of work between employment and self-employment: Emerging challenges and future research directions. Frontiers in Sociology. https://doi.org/10.3389/fsoc.2019.00086.

Pedersini, R. (2002). Economically dependent workers, employment law and industrial relations. European industrial relations observatory (EIRO) comparative study. Dublin: European Foundation for the Improvement of Working and Living Conditions. http://www.eurofound.europa.eu/eiro/2002/ 05/study/tn0205101s.htm.

Rueda, D. (2014). Dualization, crisis and the welfare state. Socio-Economic Review, 12(2), 381-407. https://doi.org/10.1093/ser/mwu015

Semenza, R., \& Pichault, F. (2019). The challenges of self-employment in Europe. Edward Elgar Publishing. https://doi.org/10.4337/9781788118453

Smeaton, D. (2003). Self employment: Models of change Portfolio model. Work, Employment \& Society, 17(2), 379-391.

Supiot, A. (1999). The transformation of work and the future of labour law in Europe: A multidisciplinary perspective. International Labour Review, 138, 31-46.

Supiot, A. (2001). Beyond employment. Changes in work and the future of labour law in Europe. Oxford University Press.

Thörnquist, A. (2015). False self-employment and other precarious forms of employment in the 'grey area' of the labour market. International Journal of Comparative Labour Law and Industrial Relations, 31(4), 411-429. http://www.kluwerlaw.com/http://urn.kb.se/resolve?urn=urn:nbn:se:liu:diva123933. Accessed 15 January 2020 
Tremblay, D. G. (2008). From casual work to economic security; The paradoxical case of self-employment. Social Indicators Research, 88(1), 115-130. https://doi.org/10.1007/s11205-007-9205-4

Van Aerden, K., Moors, G., Levecque, K., \& Vanroelen, C. (2014). Measuring employment arrangements in the European labour force: A typological approach. Social Indicators Research, 116(3), 771-791. https://doi.org/10.1007/s11205-013-0312-0

Williams, C. C., \& Horodnic, I. A. (2018). Evaluating the prevalence and distribution of dependent selfemployment: Some lessons from the European Working Conditions Survey. Industrial Relations Journal, 49(2), 109-127. https://doi.org/10.1111/irj.12206

Williams, C. C., \& Horodnic, I. A. (2019). Dependent self-employment: Theory, practice and policy. Edward Elgar Publishing. https://doi.org/10.4337/0781788118835

Publisher's Note Springer Nature remains neutral with regard to jurisdictional claims in published maps and institutional affiliations. 